\title{
Clinical evaluation of functional mitral stenosis after mitral valve repair for degenerative disease: Potential affect on surgical strategy
}

\author{
Thierry G. Mesana, MD, PhD, ${ }^{a}$ B-Khanh Lam, MD, MPH, ${ }^{a}$ Vincent Chan, MD, MPH, \\ Kristen Chen, MD, ${ }^{\mathrm{c}}$ Marc Ruel, MD, MPH, ${ }^{\mathrm{a}, \mathrm{b}}$ and Kwan Chan, $\mathrm{MD}^{\mathrm{c}}$
}

\begin{abstract}
Background: Mitral annuloplasty with either a partial band or complete ring is an integral part of mitral valve repair for degenerative disease. The affect of annuloplasty type on outcomes has not been well described. The objective of our study was to compare echocardiographic and functional characteristics of patients who underwent mitral repair with either a complete ring or a partial band.
\end{abstract}

\begin{abstract}
Methods: We evaluated 107 patients who underwent mitral repair of myxomatous degeneration at our institution by stress echocardiography, 6-minute walk testing, and short form-36 questionnaire. These assessments were performed $4.3 \pm 2.2$ years following mitral repair by a single surgeon. A band was used in 65 patients $(61 \%)$ and a ring in 42 patients $(39 \%)$. Parametric and nonparametric tests were used in the analyses.

Results: The labeled band and ring size used for repair were $30.7 \pm 2.8 \mathrm{~mm}$ and $30.4 \pm 2.1 \mathrm{~mm}$, respectively $(P=.6)$. The resting mean mitral gradient and valve area were $3.7 \pm 1.9 \mathrm{~mm} \mathrm{Hg}$ and $2.3 \pm 0.6 \mathrm{~cm}^{2}$ for patients who received a band and $5.8 \pm 2.6 \mathrm{~mm} \mathrm{Hg}$ and $1.8 \pm 0.5 \mathrm{~cm}^{2}$ for patients who received a ring (both $P<.001$ ). Distance traversed on 6-minute walk testing was $471 \pm 77 \mathrm{~m}$ in the band group and $443 \pm 107 \mathrm{~m}$ in the ring group $(P=.1)$. At peak exercise, the mean mitral gradient $(15.3 \pm 8.2 \mathrm{~mm} \mathrm{Hg}$ vs $10.6 \pm 4.8 \mathrm{~mm} \mathrm{Hg}$; $P<.001)$ and right ventricular systolic pressure $(52.6 \pm 14.2 \mathrm{~mm} \mathrm{Hg}$ vs $45.8 \pm 9.5 \mathrm{~mm} \mathrm{Hg} ; P=.004)$ were higher for patients who received a ring versus a band. Ring patients reported lower levels of energy $(P=.02)$ and general health $(P=.007)$ on short form-36 assessment.
\end{abstract}

Conclusions: Annuloplasty using a complete ring may be associated with a higher mitral valve gradient at rest and at peak exercise in certain patients. These patients may also have worse quality of life. In view of these findings, we recommend careful consideration of annuloplasty type and size at the time of mitral repair of organic disease. (J Thorac Cardiovasc Surg 2013;146:1418-25)

Mitral valve repair is the preferred approach in managing patients with mitral regurgitation (MR) due to degenerative disease. ${ }^{1}$ Although various techniques for mitral valve repair have been well described, ${ }^{2,3}$ valve repair in this population typically involves leaflet resection, annulus plication, and annuloplasty. ${ }^{4,5}$ These surgical maneuvers may theoretically result in some degree of narrowing of the mitral valve orifice.

Mitral stenosis following mitral valve repair is not well described. It has been reported in the context of pannus overgrowth from the annuloplasty ring, and also in patients who have received small mitral annuloplasty rings. ${ }^{6,7}$ The

From the Division of Cardiac Surgery, ${ }^{\text {a }}$ Department of Epidemiology and Community Medicine, ${ }^{\mathrm{b}}$ and Division of Cardiology, ${ }^{\mathrm{c}}$ University of Ottawa, Ottawa, Ontario, Canada.

Disclosures: Authors have nothing to disclose with regard to commercial support.

Read at the 93rd Annual Meeting of The American Association for Thoracic Surgery, Minneapolis, Minnesota, May 4-8, 2013.

Received for publication April 27, 2013; revisions received July 21, 2013; accepted for publication Aug 1, 2013; available ahead of print Sept 30, 2013.

Address for reprints: Thierry G. Mesana, MD, PhD, University of Ottawa Heart Institute, 3402-40 Ruskin St, Ottawa, Ontario, K1Y 4W7, Canada (E-mail: tmesana@ottawaheart.ca).

$0022-5223 / \$ 36.00$

Copyright (c) 2013 by The American Association for Thoracic Surgery

http://dx.doi.org/10.1016/j.jtcvs.2013.08.011 type of ring annuloplasty may also predispose to the development of mitral stenosis following valve repair. ${ }^{8}$ Novel in vivo preclinical data confirms that commonly used annuloplasty rings reduce the maximum mitral valve opening despite true-sizing. ${ }^{9}$ Complete rigid rings, which are commonly used in contemporary mitral valve repair, have been shown to reduce the anterior mitral leaflet intercommissural dimension at end-diastole. ${ }^{10}$ As yet, no data is available on the use of partial bands in mitral repair, which may reduce the intercommissural distance of the mitral valve to a lesser degree than complete rings.

We therefore performed a prospective assessment of 107 patients who underwent mitral valve repair of severe MR due to myxomatous disease between 2001 and 2010. To objective of our study was to compare the use of partial bands with complete rings in regard to stress echocardiography to determine peak and mean mitral valve gradients, and functional status via the short-form 36 (SF-36) assessment tool, 6-minute walk test, and plasma brain natriuretic peptide (BNP) levels.

\section{METHODS}

\section{Ethics Approval and Funding}

This study was approved by the local institutional research ethics board and written informed consent was obtained for all patients. Funding for this 


\section{Abbreviations and Acronyms \\ $\mathrm{BNP}=$ brain natriuretic peptide \\ $\mathrm{MR}=$ mitral regurgitation \\ SF-36 $=$ short form-36}

study was obtained via an unrestricted educational research grant from the University of Ottawa Heart Institute.

\section{Patients and Follow-up}

Between 2001 and 2010, 577 patients underwent mitral valve repair for degenerative disease as part of the complex mitral valve disease clinic at the University of Ottawa Heart Institute. Notably, all mitral valve repairs were performed by a single surgeon. Of these, 570 patients underwent mitral valve annuloplasty with either a complete ring (Duran Ancore, Medtronic Inc, Minneapolis, Minn, in 62 and Carpentier-Edwards Physio Annuloplasty Ring, Baxter Healthcare Corp, Irvine, Calif, in 37) or a partial band (Medtronic Futureband [Medtronic Inc, Minneapolis, Minn] in 468 and Cosgrove-Edwards Annuloplasty System [Edwards Lifesciences, Irvine, Calif] in 3). For these 570 patients, 5 -year freedom from recurrent $\mathrm{MR} \geq 2+$ and $\geq 3+$ was $90 \% \pm 2 \%$ and $98 \% \pm 1 \%$, respectively.

Two hundred eighty-eight patients with myxomatous disease were approached for enrollment in this prospective study. These patients were approached based on the hypothesis that patients with excess of mitral leaflet tissue would require more aggressive resection techniques, and therefore predispose to functional mitral stenosis following repair. Of these, 107 patients who received mitral annuloplasty with either a partial ring or a complete band agreed to participate. Reasons for patients to decline participation included the inability to exercise in 13 , refusal to participate in 18, and geographic distance from the study center in 27. Twenty-five patients were deceased, 8 had recurrent $\mathrm{MR} \geq 2+, 3$ underwent mitral valve repair without annuloplasty owing to severe mitral annular calcification, 18 had known severe left ventricle dysfunction at the time of the study, and the remaining 69 patients declined participation for other reasons. Patients were subjected to stress echocardiography, a 6-minute walk test, BNP analysis, and SF-36 assessment performed on the same day $4.3 \pm 2.2$ years (median, 4.3 years; range, $0.5-8.7$ years) following mitral valve repair. The follow-up interval was $>5$ years in 47 patients $(44 \%)$. These patients were also routinely assessed following mitral valve repair with serial clinical and echocardiographic follow-up per our institutional standard. Over the course of follow-up, there was no patients in this series with $>1+$ MR.

\section{Echocardiography}

Echocardiographic assessments were performed at rest according to established criteria. ${ }^{11}$ The mean and peak transmitral pressure gradients were calculated using the modified Bernoulli equation. The mitral valve area was calculated by the continuity equation using the stroke volume in the left ventricular outflow tract divided by the velocity time integral of the mitral transvalvular diastolic velocity. The pulmonary systolic pressure was calculated based on the tricuspid regurgitant velocity and the estimated right atrial pressure. Echocardiographic measurements were also made at peak exercise using supine bicycle ergometry that allowed up to a $40^{\circ}$ tilt. With this protocol, each patient pedaled against a fixed resistance, and after establishing an initial workload of 25 Watts for 2 minutes, the workload was increased in a stepwise fashion by 25 Watts every 2 minutes. This was a symptom-limited exercise test and patients were encouraged to exercise to exhaustion. Heart rate, blood pressure, and electrocardiogram were monitored during different stages of exercise. In addition, echocardiographic and Doppler assessment were obtained. BNP measurements were made at rest and 15 minutes following peak exercise. Six-minute walk tests were performed at least 1 hour after echocardiographic assessments to ensure an adequate rest period. Following the 6-minute walk test, each patient was asked to complete a SF-36 assessment.

\section{Operative Technique}

All mitral valve repairs were performed with median sternotomy, cardiopulmonary bypass, and cardioplegic arrest with cold blood cardioplegia. Annuloplasty sizing was identical if a band or a ring was implanted and corresponded to the intertrigonal distance; no oversizing or undersizing was employed. In patients with a large annulus and posterior leaflet prolapse, leaflet resection and sliding plasty was performed. ${ }^{12}$ Techniques used to correct anterior leaflet prolapse included chordal transfer, artificial neochord placement, or the hybrid flip-over technique. ${ }^{13}$

Resection techniques were preferred for patients with extensive leaflet tissue excess, in particular in patients with a posterior leaflet height $>1 \mathrm{~cm}$. In some patients, an edge-to-edge technique was employed, either central or commissural. In all patients who underwent mitral valve repair, $\mathrm{MR}>1+$ at the time of the index operation was an indication for further mitral valve intervention. A target mean mitral gradient $\leq 5 \mathrm{~mm} \mathrm{Hg}$ following repair was considered acceptable, although in 3 patients in our series, serial intraoperative echocardiographic assessments yielded a mean mitral gradient that increased from $<5 \mathrm{~mm} \mathrm{Hg}$ to between 5 and $7 \mathrm{~mm} \mathrm{Hg}$ with hyperdynamic cardiac function. In these patients, the mitral valve area was $\geq 2.5 \mathrm{~cm}^{2}$, therefore no further mitral valve intervention was performed. No instances of systolic anterior motion of the mitral valve were observed in this series.

\section{Statistical Analysis}

Data were imported and analyzed in SAS version 9.1 (SAS Institute Inc, Cary, NC). Continuous variables were expressed as a mean \pm standard deviation whereas categorical variables were described as a percentage of the total. Continuous data were compared with a Student $t$ test when normally distributed and with a Wilcoxon rank sum test when data were skewed. Categorical variables were compared with a $\chi^{2}$ test or Fisher exact test, when count was $<5$.

\section{RESULTS}

\section{Patient and Operative Characteristics}

Patients who received either a complete ring or partial band annuloplasty were similar in terms of age, gender, and the proportion of who had preoperative atrial fibrillation (Table 1). However, patients who received a partial band were more likely to undergo mitral valve repair for asymptomatic MR (Table 1). Bileaflet prolapse was observed in 47 patients $(44 \%), 30$ who received a band, and 17 who received a ring $(P=.6)$. The proportion of patients with prolapse of $\geq 2$ anterior leaflet scallops or $\geq 2$ posterior leaflet scallops was also similar between groups (Table 1).

Posterior leaflet resection was performed in 48 patients who received a band and in 30 who received a ring $(P=.8)$. There was also no difference between groups in regard to the proportion of patients who received sliding plasty of the posterior mitral annulus $(P=.7)$. Groups were also similar in regard to the proportion of patients who underwent placement of artificial neochordae $(P=.4)$, chordal transfer $(P=.9)$, or use of an edge-to-edge repair $(P=.3)$. Of note, the hybrid flip-over technique was only used in patients who underwent annuloplasty with a 
TABLE 1. Preoperative patient characteristics

\begin{tabular}{|c|c|c|c|}
\hline Characteristic & $\begin{array}{l}\text { Band* } \\
(\mathbf{n}=65)\end{array}$ & $\begin{array}{c}\text { Ring } \dagger \\
(\mathrm{n}=\mathbf{4 2})\end{array}$ & $\begin{array}{c}P \\
\text { value }\end{array}$ \\
\hline \multicolumn{4}{|l|}{ Patient demographics } \\
\hline Age, y & $60.7 \pm 12.1$ & $59.4 \pm 10.7$ & .5 \\
\hline Asymptomatic MR & $30(46)$ & $9(21)$ & .02 \\
\hline Atrial fibrillation $\ddagger$ & $11(17)$ & $7(17)$ & .9 \\
\hline Chronic renal failure $\S$ & $8(12)$ & $4(10)$ & .7 \\
\hline Follow-up interval, y & $6.3 \pm 1.4$ & $3.0 \pm 1.6$ & $<.00$ \\
\hline Hypertension & $18(27)$ & $15(36)$ & .4 \\
\hline Male gender & $43(66)$ & $33(79)$ & .2 \\
\hline Smoking $\|$ & $35(53)$ & $24(58)$ & .7 \\
\hline \multicolumn{4}{|l|}{$\begin{array}{l}\text { Preoperative echocardiographic } \\
\text { characteristics }\end{array}$} \\
\hline Bileaflet prolpase & $30(46)$ & $17(41)$ & .6 \\
\hline Posterior prolapse & $65(100)$ & $41(97)$ & .2 \\
\hline Prolapse $\geq 2$ anterior leaflet scallops & $19(29)$ & $7(17)$ & .2 \\
\hline Prolapse $\geq 2$ posterior leaflet scallops & $28(43)$ & $15(36)$ & .5 \\
\hline \multicolumn{4}{|l|}{ Operative characteristics } \\
\hline Annular plication & $5(8)$ & $3(7)$ & .9 \\
\hline Artificial neochordae & $6(14)$ & $14(22)$ & .4 \\
\hline Chordal transfer & $11(26)$ & $16(25)$ & .9 \\
\hline Edge-to-edge repair & $7(11)$ & $7(17)$ & .3 \\
\hline Mean annuloplasty size, $\mathrm{mm}$ & $30.7 \pm 2.8$ & $30.4 \pm 2.1$ & .6 \\
\hline Posterior leaflet resection & $48(74)$ & $30(71)$ & .8 \\
\hline Sliding plasty & $38(58)$ & $26(62)$ & .7 \\
\hline
\end{tabular}

Data are presented as $\mathrm{n}(\%)$ or mean \pm standard deviation. $M R$, Mitral regurgitation. *Includes the Medtronic Futureband (Medtronic Inc, Minneapolis, Minn). $\dagger$ Includes the Duran Ancore Ring (Medtronic Inc, Minneapolis, Minn) and the Carpentier-

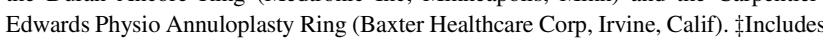
permanent atrial fibrillation preoperatively. §Includes patients with creatinine clearance $<90 \mathrm{cc} / \mathrm{min}$. ||Includes patients who were active smokers before surgery.

partial band. Overall, the mean labeled annuloplasty size implanted at surgery was not different between groups $(P=.6)$.

Among patients who received a complete ring, the average labeled annuloplasty size was also similar between those who received a Duran Ancore ring or a CarpentierEdwards Physio Annuloplasty Ring (30.5 $\pm 2.3 \mathrm{~mm}$ vs $30.1 \pm 1.7 ; P=.6)$.

\section{Echocardiographic Characteristics at Rest and at Peak Exercise}

Patients who underwent mitral annuloplasty with a complete ring had a higher resting mean mitral valve gradient compared with those patients who received a partial band $(5.8 \pm 2.6 \mathrm{~mm} \mathrm{Hg}$ vs $3.8 \pm 1.0 \mathrm{~mm} \mathrm{Hg} ; P<.001)$ (Figure 1). For all band sizes implanted in this cohort, the mean resting mitral valve gradient was $<5 \mathrm{~mm} \mathrm{Hg}$ (Figure 2). However, the mean resting mitral valve gradient was $>5 \mathrm{~mm} \mathrm{Hg}$ for all implanted rings that were $<30 \mathrm{~mm}$ (Figure 2). Overall, 31 patients had a resting mean mitral gradient $>5 \mathrm{~mm} \mathrm{Hg}, 19$ of whom underwent mitral repair with a complete ring. Nine patients had a mean mitral gradient $>8 \mathrm{~mm} \mathrm{Hg}, 7$ of whom received a complete ring,

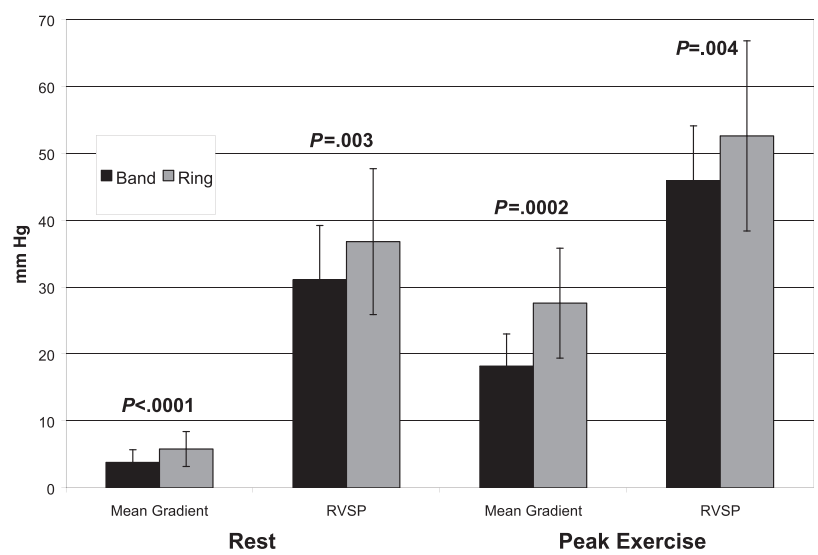

FIGURE 1. Mitral valve gradients and pulmonary pressures at rest and at peak exercise following mitral valve repair. $R V S P$, Resting right ventricular systolic pressure.

6 with a flexible ring $(27-31 \mathrm{~mm})$ and 1 with a $28 \mathrm{~mm}$ rigid ring. Only 2 patients with a partial band had a mean mitral gradient $>8 \mathrm{~mm} \mathrm{Hg}$. These 2 patients underwent repair with a $28 \mathrm{~mm}$ and a $32 \mathrm{~mm}$ annuloplasty, respectively, in addition to an edge-to-edge repair. The resting right ventricular systolic pressure was also higher in patients who received a complete ring compared with a partial band $(36.8 \pm 10.9 \mathrm{~mm} \mathrm{Hg}$ vs $31.1 \pm 8.1 \mathrm{~mm} \mathrm{Hg}$; $P=.003$ ) (Figure 2). Mitral valve area was also smaller $\left(1.8 \pm 0.5 \mathrm{~cm}^{2}\right.$ vs $\left.2.3 \pm 0.6 \mathrm{~cm}^{2} ; P<.001\right)$ and indexed left atrial volume $\left(45.7 \pm 13.7 \mathrm{~mL} / \mathrm{m}^{2}\right.$ vs $35.8 \pm 10.4$ $\left.\mathrm{mL} / \mathrm{m}^{2} ; P<.001\right)$ greater for patients who received a complete ring compared with a partial band (Table 2).

Notably, the difference in mean mitral valve gradient between annuloplasty type was more pronounced at peak exercise. The mean mitral gradient at peak exercise was $15.4 \pm 8.2 \mathrm{~mm} \mathrm{Hg}$ for patients in the ring group compared with $10.6 \pm 4.8 \mathrm{~mm} \mathrm{Hg}$ for patients in the band group $(P<.001)$. The mean mitral valve gradient at peak exercise was $>10 \mathrm{~mm} \mathrm{Hg}$ for patients who received a partial band $<32 \mathrm{~mm}$, whereas the mean mitral valve gradient was $>10 \mathrm{~mm}$ for patients who received a complete ring $<34 \mathrm{~mm}$ (Figure 2). Right ventricular systolic pressure under stress was also higher for patients who received a complete ring versus a partial band $(52.6 \pm 14.2 \mathrm{~mm}$ $\mathrm{Hg}$ vs $45.9 \pm 9.5 \mathrm{~mm} \mathrm{Hg} ; P=.004$ ) (Table 2).

\section{Functional Assessments}

At follow-up, the proportion of patients with New York Heart Association functional class I symptoms were similar between groups (Table 3). Importantly, of 39 patients in this study who underwent mitral valve repair of asymptomatic MR, 1 patient reported New York Heart Association functional class III symptoms in follow-up. Notably, the incidence of late postoperative atrial fibrillation was also higher in the ring group compared with the band group $(P=.006)$. 

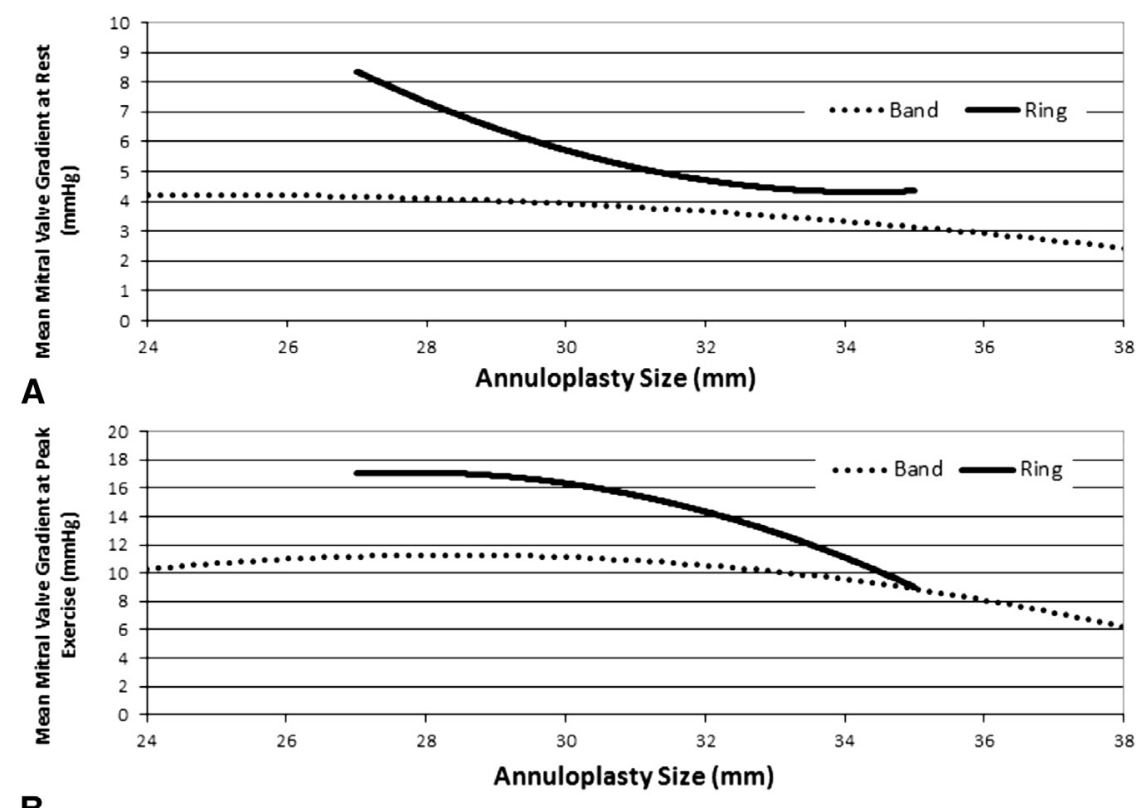

B

FIGURE 2. Mitral valve gradients according to annuloplasty size following mitral valve repair as assessments with bicycle ergometry. A, Mean mitral valve gradient at rest. B, Mean mitral valve gradient at peak exercise.

Overall, patients in both groups performed similarly in regard to the distance traversed in a 6-minute walk test. Exercise metabolic equivalents attained were also similar between groups $(P=.3)$ (Table 3$)$.

Plasma BNP levels for patients who received a complete ring were $113 \pm 101$ and $133 \pm 100$ at baseline and stress, respectively and was not different than plasma BNP levels for patients who received a band (both $P \mathrm{~s}>.1$ ).

TABLE 2. Echocardiographic measures following mitral valve repair

\begin{tabular}{lccc}
\hline \multicolumn{1}{c}{ Measure } & $\begin{array}{c}\text { Band* } \\
(\mathbf{n}=\mathbf{6 5})\end{array}$ & $\begin{array}{c}\text { Ring } \dagger \\
(\mathbf{n}=\mathbf{4 2})\end{array}$ & $\begin{array}{c}\boldsymbol{P} \\
\text { value }\end{array}$ \\
\hline Resting measures & & & \\
$\quad$ Cardiac output, L/min & $5.9 \pm 1.5$ & $5.7 \pm 1.6$ & .6 \\
$\quad$ Indexed LA volume, $\mathrm{mL} / \mathrm{m}^{2}$ & $35.8 \pm 10.4$ & $45.7 \pm 13.7$ & $<.001$ \\
LV ejection fraction, \% & $62.9 \pm 5.6$ & $63.4 \pm 6.1$ & .7 \\
LV end-diastolic diameter, mm & $47.4 \pm 4.4$ & $48.1 \pm 4.2$ & .4 \\
LV end-systolic diameter, mm & $29.8 \pm 4.2$ & $29.5 \pm 5.2$ & .7 \\
Mitral valve area, cm ${ }^{2}$ & $2.3 \pm 0.6$ & $1.8 \pm 0.5$ & $<.001$ \\
Mean mitral gradient, mm Hg & $3.8 \pm 1.9$ & $5.8 \pm 2.6$ & $<.001$ \\
Peak mitral gradient, mm Hg & $8.3 \pm 3.6$ & $12.9 \pm 4.2$ & $<.001$ \\
RVSP, mm Hg & $31.1 \pm 8.1$ & $36.8 \pm 10.9$ & .003 \\
Peak exercise measures $\ddagger$ & & & \\
Mean mitral gradient, $\mathrm{mm} \mathrm{Hg}$ & $10.6 \pm 4.8$ & $15.4 \pm 8.2$ & $<.001$ \\
Peak mitral gradient, mm Hg & $18.2 \pm 7.4$ & $27.6 \pm 11.3$ & $<.001$ \\
RVSP mm Hg & $45.9 \pm 9.5$ & $52.6 \pm 14.2$ & .004 \\
\hline
\end{tabular}

Data are presented as mean \pm standard deviation. $L A$, Left atrium; $L V$, left ventricle; $R V S P$, right ventricle systolic pressure. *Includes the Medtronic Futureband (Medtronic Inc, Minneapolis, Minn). †Includes the Duran Ancore Ring (Medtronic Inc, Minneapolis, Minn) and the Carpentier-Edwards Physio Annuloplasty Ring (Baxter Healthcare Corp, Irvine, Calif). $₫$ Peak exercise measurements were performed via bicycle ergometry.
Importantly, reported energy level $(P=.02)$ and overall general health $(P=.007)$ was rated higher on SF-36 assessment for patients who received a partial band versus a complete ring.

\section{DISCUSSION}

Mitral annuloplasty is an integral component for repair of organic mitral valve disease. ${ }^{14}$ However, the optimum annuloplasty type, whether with a flexible or rigid ring, or

TABLE 3. Functional status measures following mitral valve repair

\begin{tabular}{lccc}
\hline \multicolumn{1}{c}{ Measure } & $\begin{array}{c}\text { Band* } \\
(\mathbf{n}=\mathbf{6 5})\end{array}$ & $\begin{array}{c}\text { Ring } \dagger \\
(\mathbf{n}=\mathbf{4 2})\end{array}$ & $\boldsymbol{P}$ value \\
\hline Clinical assessment & & & \\
$\quad$ Atrial fibrillation $\ddagger$ & $12(19)$ & $18(43)$ & .006 \\
Asymptomatic at follow-up $\S$ & $43(66)$ & $22(52)$ & .2 \\
6-min walk distance, $\mathrm{m}$ & $471 \pm 78$ & $443 \pm 107$ & .1 \\
$\quad$ Exercise duration, min & $13 \pm 6$ & $13 \pm 6$ & .8 \\
$\quad$ Exercise watts & $111 \pm 47$ & $105 \pm 43$ & .5 \\
$\quad$ Exercise, METS & $5.9 \pm 1.8$ & $5.6 \pm 1.6$ & .3 \\
Biochemical assessment & & & \\
$\quad$ Plasma BNP at baseline, pg/mL & $84 \pm 81$ & $113 \pm 101$ & .1 \\
$\quad$ Plasma BNP after stress $\|, \mathrm{pg} / \mathrm{mL}$ & $113 \pm 96$ & $133 \pm 100$ & .3 \\
Short form-36 assessment & & & \\
$\quad$ Energy level & $65 \pm 21$ & $55 \pm 21$ & .02 \\
General health & $73 \pm 15$ & $63 \pm 22$ & .007 \\
\hline
\end{tabular}

Data are presented as mean \pm standard deviation or $\mathrm{n}(\%)$. METS, Metabolic equivalents; $B N P$, brain natriuretic peptide. *Includes the Medtronic Futureband (Medtronic Inc, Minneapolis, Minn). †Includes the Duran Ancore Ring (Medtronic Inc, Minneapolis, Minn) and the Carpentier-Edwards Physio Annuloplasty Ring (Baxter Healthcare Corp, Irvine, Calif). łIncludes permanent atrial fibrillation. $\S$ Represents patients with New York Heart Association functional class I symptoms at follow-up. ||Blood samples were taken 15 minutes after achieving peak exercise. 
a complete ring or partial band, is debatable. In our study, we compared outcomes of patients following mitral valve repair with either a complete ring or a partial band. Detailed echocardiographic and functional assessments were performed on a subset of patients with myxomatous disease at an average of 4.3 years following surgery. These investigations confirmed higher mitral gradients and pulmonary pressures in patients who received a complete ring at the time of mitral repair. In fact, these echocardiographic differences were also associated with a worse functional status for patients who received a complete ring.

Although this study was not a randomized comparison, patient comorbidities were similar between those who received either a complete ring or a partial band. Mitral valve lesions were also similar between groups in terms of the proportion presenting with bileaflet prolapse or the proportion with multiscallop anterior/posterior leaflet prolapse. Overall, patients in our study had similar characteristics to patients in other series describing mitral repair of myxomatous degeneration. ${ }^{15-18}$ Importantly, the surgical strategy aside from annuloplasty type was similar between groups. Sizing of the mitral annulus was performed considering the intertrigonal distance and was not different between groups. There was also no difference between groups in the use of sliding plasty or edge-to-edge repair. Naturally, sliding plasty with associated annular compression would reduce the orifice area of the mitral valve, and the edge-to-edge repair has been associated with a smaller effective orifice area in in vitro studies. ${ }^{19}$ Nonresection based strategies are suggested to provide a larger mitral orifice area early after repair, although the differences in mitral orifice area between resection and nonresection strategies may not be sustained beyond the first year following repair. ${ }^{3,20}$ Nevertheless, the comparison of annuloplasty type in this study seems appropriate because groups were similar in regard to prolapse pathology, annulus sizing, and the use of resection or annular reduction techniques.

Although patients were managed with a similar surgical strategy, those who received a complete ring had higher mean mitral gradients at rest and at peak exercise. This was observed despite the fact that mean mitral gradients were $<5 \mathrm{~mm}$ intraoperatively at the time of mitral valve repair thereby highlighting the need for serial assessments after mitral repair. In fact, the threshold mean mitral gradient above which functional mitral stenosis may occur remains unclear. Although current guidelines categorize mitral stenosis as mild if the mean gradient $<5 \mathrm{~mm},{ }^{11}$ the normal mean mitral gradient may be $<2 \mathrm{~mm} \mathrm{Hg}$ in some adults. ${ }^{21}$ Therefore, annular or subvalvular manipulation may impart some degree of stenosis.

Notably, the mean mitral gradient at peak exercise was $>10 \mathrm{~mm}$ for all patients who received a ring annuloplasty $<34 \mathrm{~mm}$. The higher mitral gradients in patients who received a ring were also observed with higher pulmonary pressures and larger left atrial volumes. Therefore, these hemodynamic changes were associated with structural changes of the heart years following repair. These changes may explain the higher incidence of atrial fibrillation in patients who received a complete ring. Most notably, there were also differences in the quality of life following repair, which may relate to the hemodynamic differences observed on echocardiography. Plasma BNP levels were not different between groups. Although BNP levels have been associated with worse survival and more cardiac events in patients with heart failure, reported thresholds in the published literature vary and may relate to the duration of symptoms and patient factors. $^{22}$

To our knowledge, this report constitutes 1 of the first detailed reports describing functional mitral stenosis following mitral valve repair in the published literature. The concept of having a small valve orifice is well described in the valve replacement literature. We have previously shown that an indexed effective orifice area $<1.25 \mathrm{~cm} / \mathrm{m}^{2}$ following mitral valve replacement is associated with recurrent congestive heart failure and worse survival following mitral valve replacement. ${ }^{23}$ No clinical data is available describing the mitral orifice area in patients following mitral repair, although preclinical data has been performed comparing various ring types. These data suggest that nonsaddle-shaped complete rings may increase anterior mitral leaflet strain, ${ }^{24}$ and confirm that complete rigid rings reduce the anterior mitral leaflet commissurecommissure dimension at end-diastole. ${ }^{10}$ Although we present no data confirming this, it may be possible that the altered movement of the anterior leaflet may result in functional stenosis.

In this series, higher mitral gradients were observed in patients with rigid or flexible complete rings. It is our preference to use a semi rigid band, which in our opinion provides remodeling for most of the mitral orifice while preserving the most anterior aspect of the annulus that corresponds to the intertrigonal area. This preserves the natural saddle of the mitral valve and may allow for more physiologic motion of the anterior leaflet. Therefore, this may represent an advantage of partial bands to certain complete rings, especially in patients with a small mitral annulus as demonstrated in this study. It is possible that saddle-shaped rings may reduce the risk of functional mitral stenosis, particularly in those patients who require an annuloplasty $\leq 30 \mathrm{~mm}$.

Excessive pannus formation after annuloplasty has been described as a cause of mitral stenosis in isolated cases, ${ }^{6}$ but is not a common cause of reoperation after mitral valve repair. Overall, none of the patients in our series demonstrated a degree of mitral stenosis or symptoms sufficient to require reoperation. In fact, mitral stenosis following valve repair in this population was rare, but 
functional mitral stenosis was observed in a subset of patients. The findings of our study are unique; traditional assessments of valve outcomes do not include stress echocardiography. ${ }^{17-19}$ Nevertheless, we have demonstrated that suboptimal repair can include obstructive annuloplasty and may be important in active individuals who are able to generate higher gradients during exercise. Therefore, serial assessments of mitral valve function following repair should include surveillance of stenosis in addition to regurgitation.

\section{Limitations}

This is a nonrandomized comparison of patients who underwent mitral repair with either a ring or a band; therefore, there may be unknown differences between groups that may have influenced outcomes. Patients included in our study comprised a small subset of patients who underwent mitral valve surgery at our institution during this time period. Therefore, results should not be generalized to describe all outcomes following repair of myxomatous degeneration. Patients in our study were also healthy with few comorbidities, so extending the conclusions of this study to sick patients, or to patients with other causes of MR, is not appropriate. Because this was a cross-sectional cohort study, detailed stress echocardiography and clinical assessments were made at different time points following mitral repair. Conclusions regarding the temporal progression of mitral stenosis following repair cannot be made.

\section{CONCLUSIONS}

Annuloplasty using a complete ring may be associated with higher mitral valve gradients at rest and at peak exercise in certain patients. These patients may also have worse quality of life. In view of these findings, we recommend careful consideration of annuloplasty type and size at the time of mitral repair of organic disease.

\section{References}

1. Gammie JS, Sheng S, Griffith BP, Peterson ED, Rankin JS, O'Brien SM, et al. Trends in mitral valve surgery in the United States: results from the Society of Thoracic Surgeons Adult Cardiac Surgery Database. Ann Thorac Surg. 2009; 87:1431-7; discussion 1437-9.

2. David TE, Armstrong S, Ivanov J. Chordal replacement with polytetrafluoroethylene sutures for mitral valve repair: a 25-year experience. J Thorac Cardiovasc Surg. 2013;145:1563-9.

3. Falk V, Seeburger J, Czesla M, Borger MA, Willige J, Kuntze T, et al. How does the use of polytetrafluoroethylene neochordae for posterior mitral valve prolapse (loop technique) compare with leaflet resection? A prospective randomized trial. J Thorac Cardiovasc Surg. 2008;136:1205; discussion 1205-6.

4. Jouan J, Berrebi A, Chauvaud S, Menasché P, Carpentier A, Fabiani JN. Mitral valve reconstruction in Barlow disease: long-term echographic results and implications for surgical management. J Thorac Cardiovasc Surg. 2012; 143(4 Suppl):S17-20.

5. Chan V, Ruel M, Chaudry S, Lambert S, Mesana TG. Clinical and echocardiographic outcomes after repair of mitral valve bileaflet prolapse due to myxomatous disease. J Thorac Cardiovasc Surg. 2012;143(4 Suppl):S8-11.

6. Ibrahim MF, David TE. Mitral stenosis after mitral valve repair for non-rheumatic mitral regurgitation. Ann Thorac Surg. 2002;73:34-6.
7. Song S, Cho SH, Yang JH, Park PW. Repair for mitral stenosis due to pannus formation after Duran ring annuloplasty. Ann Thorac Surg. 2010;90:e93-4.

8. Chung CH, Kim JB, Choo SJ, Kim KS, Song H, Song MG, et al. Long-term outcomes after mitral ring annuloplasty for degenerative mitral regurgitation: Duran ring versus Carpentier-Edwards ring. J Heart Valve Dis. 2007;16: 536-44; discussion 544-5.

9. Bothe W, Kvitting JP, Swanson JC, Göktepe S, Vo KN, Ingels NB, et al. How do annuloplasty rings affect mitral leaflet dynamic motion? Eur J Cardiothorac Surg. 2010;38:340-9

10. Bothe W, Kvitting JP, Swanson JC, Hartnett S, Ingels NB Jr, Miller DC. Effects of different annuloplasty rings on anterior mitral leaflet dimensions. J Thorac Cardiovasc Surg. 2010;139:1114-22.

11. Douglas PS, Garcia MJ, Haines DE, Lai WW, Manning WJ, Patel AR, et al ACCF/ASE/AHA/ASNC/HFSA/HRS/SCAI/SCCM/SCCT/SCMR 2011 appropriate use criteria for echocardiography. A report of the American College of Cardiology Foundation Appropriate Use Criteria Task Force, American Society of Echocardiography, American Heart Association, American Society of Nuclear Cardiology, Heart Failure Society of America, Heart Rhythm Society, Society for Cardiovascular Angiography and Interventions, Society of Critical Care Medicine, Society of Cardiovascular Computed Tomography, and Society for Cardiovascular Magnetic Resonance Endorsed by the American College of Chest Physicians. J Am Coll Cardiol. 2011;57:1126-66.

12. Mesana T, Ibrahim M, Hynes M. A technique for annular plication to facilitate sliding plasty after extensive mitral valve posterior leaflet resection. Ann Thorac Surg. 2005;79:655-65.

13. Mesana T, Ibrahim M, Kulik A, Ruel M, Dover K, Nicholson D, et al. The "hybrid flip-over" technique for anterior leaflet prolapse repair. Ann Thorac Surg. 2007;83:322-3

14. Verma S, Mesana TG. Mitral-valve repair for mitral-valve prolapse. $N$ Engl J Med. 2009;361:2261-9.

15. Spiegelstein D, Moshkovitz Y, Sternik L, Fienberg MS, Kogan A, Malachy A, et al. Midterm results of mitral valve repair: closed versus open annuloplasty ring. Ann Thorac Surg. 2010;90:489-95.

16. DiBardino DJ, ElBardissi AW, McClure RS, Razo-Vasquez OA, Kelly NE, Cohn LH. Four decades of experience with mitral valve repair: analysis of differential indications, technical evolution, and long-term outcome. $J$ Thorac Cardiovasc Surg. 2010;139:76-83; discussion 83-4

17. Seeburger J, Borger MA, Doll N, Walther T, Passage J, Falk V, et al. Comparison of outcomes of minimally invasive mitral valve surgery for posterior, anterior and bileaflet prolapse. Eur J Cardiothorac Surg. 2009;36:532-8.

18. Castillo JG, Anyanwu AC, Fuster V, Adams DH. A near 100\% repair rate for mitral valve prolapse is achievable in a reference center: implications for future guidelines. J Thorac Cardiovasc Surg. 2012;144:308-12.

19. Jimenez JH, Forbess J, Croft LR, Small L, He Z, Yoganathan AP. Effects of annular size, transmitral pressure, and mitral flow rate on the edge-to-edge repair: an in vitro study. Ann Thorac Surg. 2006;82:1362-8.

20. Seeburger J, Falk V, Borger MA, Passage J, Walther T, Doll N, et al Chordae replacement versus resection for repair of isolated posterior mitral leaflet prolapse: à ègalité. Ann Thorac Surg. 2009;87:1715-20.

21. Royce C, Donnan G, Royse A. Assessing the basic hemodynamic state. In Royce C, Donnan G, Royse A, eds. Pocket guide of perioperative and critical care echocardiography. New York: McGraw-Hill Medical; 2006:30-45.

22. Doust JA, Pietrzak E, Dobson A, Glasziou P. How well does B-type natriuretic peptide predict death and cardiac events in patients with heart failure: systematic review. BMJ. 2005;330:625.

23. Lam BK, Chan V, Hendry P, Ruel M, Masters R, Bedard P, et al. The impact of patient-prosthesis mismatch on late outcomes after mitral valve replacement J Thorac Cardiovasc Surg. 2007;133:1464-73.

24. Bothe W, Kuhl E, Kvitting JP, Rausch MK, Göktepe S, Swanson JC, et al. Rigid, complete annuloplasty rings increase anterior mitral leaflet strains in the norma beating ovine heart. Circulation. 2011;124(11 Suppl):S81-96.

\section{Discussion}

Dr David H. Adams (New York, NY). I envy very much your dedicated mitral valve disease clinic and outcomes center, which I saw firsthand during a recent visit. I also applaud your dedication to follow-up of patients after mitral valve repair and absolutely agree that we have a responsibility to get echocardiographic and 
clinical follow-up on patients following operation, particularly because guidelines recommend early intervention in asymptomatic patients.

Having said that, I think this particular effort to convince us to stop using complete rings to potentially limit the degree of functional mitral stenosis following repair falls well short of the mark. Other than ring type, there are several key differences in your 2 groups that are worthy of comment. First, in your previous publication last year on patients with bileaflet prolapse and echocardiographic outcome, many of whom I'm sure reappeared for this analysis, you stated that you have been using future bands exclusively since 2004 . We all know we are resecting less tissue and focusing more on techniques that preserve leaflet mobility in recent years. Any potential change in functional results are just as likely to be due to better leaflet strategies as opposed to annuloplasty choice. For example, your use of edge-to-edge sutures is higher in the ring group, and these were used in the earlier era, and my guess is that explains some of your outcomes on an exercise bike.

Furthermore, we need to know the interval between the surgical date and the study echo in each group, as you point out. All of the rings were used very early in your series-before 2004. Leaflet thickening and pannus formation are temporal events and may again explain some of your findings.

Third, by my calculation, $42 \%$ of your ring patients returned to participate in this study whereas only $13 \%$ of the band patients signed up. Either there was a significant recruitment bias or other factors are in play. This is another issue that needs comment.

The other key difference worth highlighting when considering your Short Form-36 data is that $46 \%$ of patients in your band group were operated on and were asymptomatic at the time of surgery compared with only $21 \%$ in the ring group. I'm pretty sure that it is easier to make an asymptomatic patient feel good after surgery versus a symptomatic one.

Here are a few final questions. We tend to see what we want to see on echos. In your article last year on bileaflet prolapse, you described excellent echo outcomes with only 1 case that developed stenosis in 142 patients. In this study, was your echo team blinded to the reason for the follow-up study echo and blinded to the ring type in this analysis? How do you reconcile the differences in your findings in this study and your former?

You note in your article that you choose rings based on the intertrigonal distance measured with sizers. That is another potential issue, because the notches on the future band sizers correlate to trigones according to the manufacturer, whereas on the Physio ring (Carpentier-Edwards Physio Annuloplasty Ring [Baxter Healthcare Corp, Irvine, Calif]) they correlate to the commissures. If you chose sizes as stated in your article, you would have necessarily downsized the Physio rings. Please clarify that for us.

Finally, in your article you state there were no patients that developed $>1+$ mitral regurgitation during any time of follow-up. That is very unusual. We know from our series and those of Dr David and others, that $0.5 \%$ per year to $1 \%$ per year develop recurrent, significant mitral regurgitation. Can you clarify that for us?

I respect your group a lot, but you are comparing apples and oranges, and this question of ring versus band and functional outcomes needs further study.
Dr Thierry Mesana (Ottawa, Ontario, Canada). Thank you for those well-made points. I would like to answer the last question very quickly. I never said I had no patients with $>1+$ mitral regurgitation. I said that in this study when we recruited patients we were careful there was no patient with $>1+$ mitral regurgitation. So in this study there are no patients with mitral regurgitation who could compromise the analysis of the data.

It is true that there is a lot of bias in this study, because most of these rings were used at the very early stage of the last decade of practice at the Heart Institute, and then we moved roughly after 2004 into the use of bands, because basically we have seen some patients with symptomatic mitral stenosis after implantation of a ring. I was approached by cardiologists who wanted to do this study because they wanted to understand what was going on. And in this study, the common point between the 2 groups is that there is no difference in techniques other than the use of band versus ring. Indeed, we have evolved in the past 3 or 4 years-doing less sliding plasty and less aggressive resection of the valve. There is no doubt of this. But in this study, most patients had more than 5 years' follow-up, and they are more likely to be recipients of the oldest way of practicing mitral valve repair; that is, with less Gore-Tex (W. L. Gore \& Associates, Inc, Flagstaff, Ariz) and more sliding and more leaflet resection. Nevertheless, these patients are similar, and we have identified the problem of the ring.

I believe sincerely that annuloplasty is not a benign device, and we should be more careful when we put these full rings in patients who have not a very large annulus. The problem has been identified because we follow our patients very carefully, as you mentioned initially in your comments, every year, at the Heart Institute.

It is not in contradiction with the previous article I published, which was only on bileaflet prolapse and included even more future bands than in this study where we have a cohort that is different. Did I answer the questions?

Dr Adams. That is a good start. I think it's a really interesting topic, Thierry, and I think you are really challenging us to think about it. I'm still skeptical, but you got my attention.

Dr Marek A. Deja (Katowice, Poland). It is very interesting data that you are showing. What was the total energy expenditure on exercise in both groups and was there a correlation of the gradient that you produced with the level of exercise the patient was performing? Maybe some of the patients were performing a bigger exercise. I wish I had seen the spiroergometry on these patients and seen if their exercise capacity was different.

Dr Mesana. Well, we have to understand something here. These patients are not doing badly. They are just not as good as they should be, particularly the younger patients. So we push them very hard during stress exercise. I was there a few times. They are pushed to exertion. And when you are asking cardiologists to send you patients for asymptomatic mitral regurgitation, the patient should be able to do at least as much as they were doing before. We have done a substudy of that, which is not presented here. We believe as surgeons that a mean mitral valve gradient $<5$ is fine.

Actually we did a control study at the same time as we looked at these patients. We studied 21 patients with normal native valve and normal heart function, and the cutoff line for having no gradient at exercise is a mean gradient at rest of 3 , and when we come back to 
the data and we look at all the patients who had a gradient $>3$, then all the data on symptoms became significant. So all the data that are borderline and significant become very significant. The cardiologists came to me and said, "Surgeons believe that mean gradient of 5 is right. We believe that 3 is right." So this is a debate for the future.

Dr Y. Joseph Woo (Philadelphia, Pa). Just a follow-up on the residual regurgitation issue. Do you know how many patients in the band group had at least $2+$ residual regurgitation at longterm follow-up, and were thus excluded from your analysis by intent? You may have traded 1 problem for another.
Dr Mesana. We excluded any patient in this study that had anything $>1+$.

Dr Woo. How many patients were excluded who had regurgitation?

Dr Mesana. I think there were approximately 3\% of the patients overall. Interestingly, during exercise, although 3 patients with symptomatic mitral stenosis had $2+$ mitral regurgitation during exercise, and some of these patients then became very symptomatic. But as soon as they stopped resting, they had no more mitral regurgitation. We could monitor this during exercise. 